OXYGEN ELECTRODES FOR RECHARGEABLE ALKALINE FUEL CELLS

\author{
L. Swette and J. Giner \\ Giner, Inc. \\ Waltham, Massachusetts 02254-9147
}

The primary objective of this program is the investigation and development of electrocatalysts and supports for the positive electrode of moderate temperature single-unit rechargeable alkaline fuel cells. We define the electrocatalyst as the material with a higher activity for the oxygen electrode reaction than the support. viable candidate materials must meet the following requirements: 1] good electrical conductivity (typically a more demanding requirement for supports than for electrocatalysts), 2] high resistance to chemical corrosion and electrochemical oxidation and/or reduction; 3] electrocatalysts, in addition, must exhibit high bifunctional electrocataiytic activity $\mathrm{l}_{2}$ evolution and reduction). Advanced development will require that the materials be prepared in high surface area forms, and may also entail integration of various candidate materials, e.g., one or two electrocatalysts distributed on a less active support material.

At this point in the program eight candidate support materials and seven electrocatalysts have been investigated. Of the eight supports, three materials meet the preliminary requirements in terms of electrical conductivity and stability. Emphasis has now shifted to preparation in high surface area form and testing under more severe corrosion stress conditions. Of the seven electrocatalysts prepared and evaluated, at least five materials remain as potential candidates. The major emphasis remains on preparation, physical characterization and electrochemical performance testing.

For supports, an acceptable conductivity should exceed about $1 \mathrm{ohm}-\mathrm{cm}^{-1}$. This is a difficult initial screening criterion since these materials are being drawn from metal oxides, carbides, nitrides, etc. For catalysts we anticipate that the conductivity can be more than an order of magnitude lower on a high conductivity support. In preliminary corrosion testing, the material is held at $1.4 \mathrm{~V}$ versus RHE in $30 \% \mathrm{KOH}$ at $80^{\circ} \mathrm{C}$ for 15 to 20 hours. An acceptable anodic current is on the order of a few microamps/mg of material. For more stringent corrosion testing, and for further evaluation of electrocatalysts (which generally show significant $\mathrm{O}_{2}$ evolution at $1.4 \mathrm{~V}$ ), samples will be held at $1.6 \mathrm{~V}$ or $0.6 \mathrm{~V}$ for about 100 hours. The materials and solutions will then be physically and chemically analyzed for signs of degradation.

Determining electrochemical activity for the oxygen electrode reaction requires considerable exploratory electrode preparation and testing, since the measured polarization is highly dependent on surface area and the hydrophobic/hydrophilic balance or "flooded agglomerate" configuration achieved (ref.l). For the experimental materials being studied, a customized electrode fabrication procedure has to be developed for each material. For preliminary testing, catalysts of interest should show ( $500 \mathrm{mV}$ polarization (from $1.2 \mathrm{~V}$ ) in either mode at $200 \mathrm{~mA} / \mathrm{cm}^{2}$. In advanced development we would expect to reduce the polarization to about $300-350 \mathrm{mV}$. 


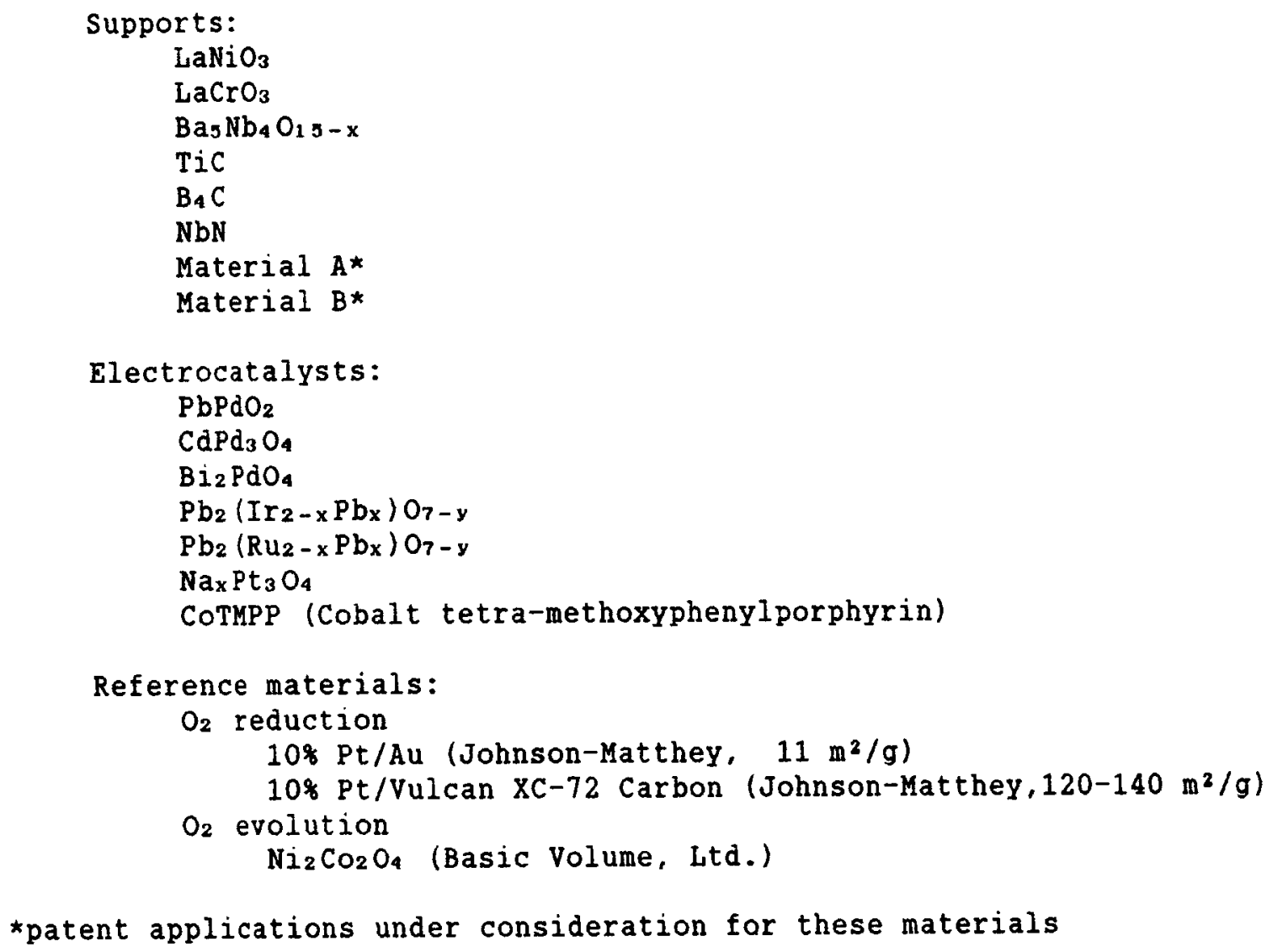

\section{MATERIAL SOURCES}

Materials have been acquired both by purchase, where commercially available, and/or by preparation. Initial preparations have tended to follow procedures documented in the literature where available and vary greatly according to reaction requirements, e.g. thermal decomposition of mixed salts (LaNiO $\left.{ }_{3}, \mathrm{LaCrO}_{3}\right), \mathrm{high}$ temperature firing of mixed reactant powders or pellets $\left(\mathrm{Bas}_{5} \mathrm{Nb}_{4} \mathrm{O}_{15-x}, \mathrm{LaCrO}_{3}\right.$, $\left.\mathrm{Nax}_{3} \mathrm{Pt}_{3} \mathrm{O}_{4}, \mathrm{PbPdO}_{2}\right)$, co-precipitation and heat treatment $\left(\mathrm{PbPdO}_{2}, \mathrm{CdPd}_{3} \mathrm{O}_{4}, \mathrm{Bi}_{2} \mathrm{PdO}_{4}\right.$, $\mathrm{Pb}_{2} \operatorname{Ir}_{2} \mathrm{O}_{7}-\mathrm{x}$ ), adsorption/thermal decomposition (COTMPP on carbon), and gas phase reactions (TiC). The emphasis has been on obtaining materials of verifiable composition and secondarily with desirable electrochemical properties such as high surface area and small particle size. Materials are typically characterized by $X-r a y$ diffraction and occasionally in conjunction with thermal gravimetric analysis (ref.2).

\section{EXPERIMENTAL METHODS}

\section{Electrical Conductivity}

The electrical conductivity of materials is estimated by compressing a small quantity of the powder at about 12000 psi between metal pistons within an insulating cylinder; the resistance of the powder is measured directly with an ohmmeter. If the resistivity thus measured is in the range of a few ohm-cm, the resistance is 
determined more accurately by measuring the voltage drop across the powder under the flow of sufficient current to generate easily measured current and voltage signals. When appropriate, a more accurate value can be obtained by a four-point method in which the voltage drop is measured across contacts separate from the current carrying metal pistons.

\section{Corrosion Resistance}

For an initial assessment of the stability of candidate support materials and catalysts, the steady-state anodic current is measured in the range of 1.0 to $1.4 \mathrm{~V}$ versus $\mathrm{RHE}$ in $\mathrm{N}_{2}$ sparged $30 \% \mathrm{KOH}$ at $80^{\circ} \mathrm{C}$. The powder to be tested is blended with PTFE (DuPont type 30 Teflon suspension) at about $10 \%$ by weight and heated to $275^{\circ} \mathrm{C}$, to try to achieve a suitable compromise between physical integrity and good electrolyte penetration. A pure gold mesh is used as the current collector and the electrode is suspended vertically in solution to prevent gas bubble occlusion of the surface. If the anodic current observed, after initiation of potentiostatic control, drops to the microamp range, the system is allowed to equilibrate overnight; the steady-state anodic current is then recorded. In a second stage of testing, candidate materials are subjected to higher potential $(1.6 \mathrm{~V})$ representative of oxygen evolution conditions, and lower potentials $(0.6 \mathrm{v})$ representative of oxygen reduction conditions. The latter is intended to place stress on the materials used in the oxide form.

The value of residual anodic current measured by these methods is not an unequivocal indicator of electrochemical stability. A low value of anodic current (e.g. a few microamps/mg) is necessary but not sufficient to demonstrate corrosion resistance since the powder may passivate or delaminate from the current collector and exhibit a deceptive value. At the other extreme, a high current may represent the onset of oxygen evolution rather than corrosion, especialiy in the case of catalytic materials. Finally, the gold current collector always exhibits a base level of anodic current. Consequently the anodic current values measured must be combined with other observations such as weight loss or gain, color changes, and microscopic examination.

\section{MEASUREMENT OF OXYGEN REDUCTION/EVOLUTION PERFORYANCE}

For determination of oxygen reduction/evolution performance, materials are tested in a floating electrode cell (ref. 3) in $30 \% \mathrm{KOH}$ at $80^{\circ} \mathrm{C}$. An appropriate electrode is fabricated by blending the powder with PTFE (typically DuPont type 30 TFE suspension, in the range of $15-60 \%$ by weight) and heating at temperatures from 300 to $360^{\circ} \mathrm{C}$. A gold-plated nickel mesh is used as the current collector. Generally, several iterations of electrode fabrication are necessary to achieve a Teflonagglomerate structure with a suitable hydrophobic/hydrophilic balance. At this stage, a single structure is not always suitable for both modes of operation.

The polarization characteristics of such electrodes are established by measuring the steady-state current density (compensated for iR loss) at controlled potential steps, using the Dynamic Hydrogen Electrode (DHE, ref. 4), as a reference (typically 2-4 $\mathrm{mV}$ negative of Reversible Hydrogen at $1 \mathrm{~mA} / \mathrm{cm}^{2}$ ). The oxygen evolution measurements can be severely compromised by gas bubble occlusion of the horizontal electrode surface, however. Thus, efforts are currently underway to develop an integral electrolyte membrane suitable for these tests and more representative of a fuel cell operating configuration. 


\section{RESULTS AND DISCUSSION}

\section{Supports}

of the eight candidate supports evaluated, LaNiO3, Material A and Material B remain as potentially suitable materials. $\mathrm{B}_{4} \mathrm{C}, \mathrm{LaCrO}_{3}$, and $\mathrm{Ba}_{5} \mathrm{Nb}_{4} \mathrm{O}_{15-x}$ did not exhibit sufficient electrical conductivity to serve as catalyst supports. Boron carbide in stoichiometric form is an insulator. A boron deficient form was reported to be conductive and was used by General Electric investigators as a support for platinum (ref. 5). Such material could not be obtained, but if it derived its conductivity from free carbon it would not be a suitable candidate in any event. oxygen deficient barium niobate was also anticipated to be conductive. Most materials prepared, however, exhibited resistivities in the range of megohm-cm, or, when significantly lower, showed evidence of residual carbon (used in the preparation). One preparation of $\mathrm{LaCrO}_{3}$, obtained by solid state reaction of $\mathrm{La}_{2} \mathrm{O}_{3}$ and black $\mathrm{Cr}_{2} \mathrm{O}_{3}$ (from thermally decomposed chromium oxalate), was considerably more conductive, but still unacceptable at about $1400 \mathrm{ohm}-\mathrm{cm}$.

The remaining candidate support materials all show high conductivity. The conductivities, in increasing order, are $\left(\mathrm{ohm}-\mathrm{cm}^{-1}\right)$ : LaNiO $_{3}(5), \operatorname{TiC}(50-200)$, Material B (125), NbN (300), Material A (390). In chemical testing of TiC, NbN, and Material A, after about 5 hours in $45 \% \mathrm{KOH}$ at $100^{\circ} \mathrm{C}$, none of the materials showed any signs of reaction such as gassing or color change, and all retained high conductivity. In electrochemical testing, however, $\mathrm{TiC}$ and $\mathrm{NbN}$ gave evidence of reactions. A TiC electrode, for example, exhibited a high anodic current even at $1.0 \mathrm{~V}$ versus RHE, e.g., about $12 \mathrm{microamps} / \mathrm{mg}$ after 22 hours in $30 \%$ KOH at $80^{\circ} \mathrm{C}$. Post-test examination by scanning electron microscopy showed signs of changes in morphology also. NbN showed a very low anodic current at $1.4 \mathrm{~V}(0.1 \mathrm{microamps} / \mathrm{mg}) \mathrm{but}$ higher currents at $1.2 \mathrm{~V}$ versus $\mathrm{RHE}$, suggesting passivation (e.g., $\mathrm{NbO}_{2}$ formation).

$\mathrm{LaNiO}_{3}$, Material $A$ and Material $B$ appear to be stable at anodic potentials in $30 \% \mathrm{KOH}$ at $80^{\circ} \mathrm{C}$. LaNiO 3 gave an anodic current of about $0.1 \mathrm{microamps} / \mathrm{mg}$ at $1.3 \mathrm{~V}$ but showed visible oxygen evolution at $1.4 \mathrm{~V}$, since it is more catalytic than the other materials. At $1.4 \mathrm{~V}$ both materials $A$ and $B$ ( 40 micron powder) show about 0.2 microamps/mg; it should be noted that the bare gold mesh current collector exhibits an anodic current of the same order of magnitude at $1.4 \mathrm{~V}$. For a higher surface area preparation of Material A ( 1 to 3 micron powder) the anodic current measured was about 1 microamps/mg at $1.4 \mathrm{~V}$ versus RHE. This same electrode was then held at $1.5 \mathrm{~V}$ for 28 hours. The anodic current was steady at $1.4 \mathrm{~mA} / \mathrm{cm}^{2} \quad(70 \mathrm{microamps} / \mathrm{mg})$; the value for $1 \mathrm{~cm}^{2}$ of bare gold mesh was $1.62 \mathrm{~mA}$. Finally, the electrode was held at $1.6 \mathrm{~V}$ for an additional 84 hours. The anodic current was about the same as for bare gold mesh, about $90-100 \mathrm{~mA} / \mathrm{cm}^{2}$. Post-test examination of the electrode showed no weight loss or gain and no visible evidence of change.

\section{ELECTROCATALYSTS}

\section{Electrical Conductivity}

Good electrical conductivity will be required for electrocatalysts that serve as both catalyst and electrode structure. For materials that may be distributed as small particles on a highly conductive support, a much lower conductivity may be tolerated since each catalyst particle will oniy need to pass a very small current a short 
distance. In anticipation of developing such a structure ultimately, some of the materials included in our present investigation are not highly conductive.

The base-metal/palladium oxides studied are examples of materials of lower conductivity; they exhibit a negative temperature coefficient of resistance characteristic of semiconductors. Lazarev and shaplygin have reported the following resistivities: $3-15 \mathrm{ohm}-\mathrm{cm}$ for $\mathrm{PbPdO}_{2}$ (ref. 6), 300-900 ohm-cm for $\mathrm{Bi}_{2} \mathrm{PdO}_{4}$ (ref. 7) and $2.1 \mathrm{ohm}-\mathrm{cm}$ for $\mathrm{CdPd}_{3} \mathrm{O}_{4}$ (ref.8). $\mathrm{CdPd}_{3} \mathrm{O}_{4}$ and $\mathrm{PbPdO}_{2}$ have been prepared with some success by co-precipitation of the metal salts and heating to about $500^{\circ} \mathrm{C}$. Both show broad line XRD patterns for the compounds with traces of the base metal oxide. $\mathrm{Bi}_{2} \mathrm{PdO}_{4}$ preparations have not been successful to date. The $\mathrm{CdPd}_{3} \mathrm{O}_{4}$ powder has a measured resistivity of $0.5 \mathrm{ohm}-\mathrm{cm}$, consistent with with the range reported for this material. The $\mathrm{PbPdO}_{2}$, however, has shown quite high resistivity (megohm-cm) in most preparation attempts, the best being about $112 \mathrm{~K}$ ohm-cm.

The measured resistivity of $\mathrm{Nax}_{3} \mathrm{Pt}_{3} \mathrm{O}_{4}$ powders has also been quite variable. Shannon, et al. (refs. 9,10) have reported metallic conductivity for single crystal $\mathrm{Na}_{1} .0 \mathrm{Pt}_{3} \mathrm{O}_{4}$, e.g. $9 \times 10^{-5} \mathrm{ohm}-\mathrm{cm}$. In our earliest attempts to prepare this material, resistivities of the powders (amorphous) were in the megohm range. In subsequent preparations (at $x=1)$, good conductivities were observed $\left(1.4\right.$ to $164 \mathrm{ohm}^{-\mathrm{cm}^{-1}}$ ) but analysis also showed 15-25\% free Pt. (ref.2). In the most recent preparations ( $\mathrm{x}=$ 0.8 , no free $\mathrm{Pt}$ ), the conductivity is on the order of $50 \mathrm{ohm}-\mathrm{cm}^{-1}$.

of the two pyrochlores to be studied, only the iridium compound has been prepared. The composition suggested is $\mathrm{Pb}_{2}\left(\mathrm{Ir}_{1} .3_{3} \mathrm{~Pb}_{0.67}\right)_{7-y}$ (ref.2). The measured conductivity of this powder was about $40 \mathrm{ohm}-\mathrm{cm}^{-1}$.

\section{Corrosion Testing}

Most of the corrosion test data for electrocatalysts is considered preliminary because the electrochemical test data is not so readily interpreted for materials that catalyze oxygen evolution.

$\mathrm{Na}_{\mathrm{Pt}} \mathrm{O}_{4}$ showed visible oxygen evolution above $1250 \mathrm{mV} \mathrm{vs}$. RHE; the anodic current measured after 16 hours at $1250 \mathrm{mV}$ was 2.6 microamps $/ \mathrm{mg}$. $\mathrm{CdPd}_{3} \mathrm{O}_{4}$ exhibited oxygen evolution above $1275 \mathrm{mV}$ vs. RHE; the anodic current measured after 15 hours at this potential was about 3.5 microamps $/ \mathrm{mg}$. $\mathrm{PbPdO}_{2}$ has too low a conductivity for a practical test of the pure material.

The Pb-Ir pyrochlore showed substantial anodic current at $1.0 \mathrm{~V}$ vs. RHE, about $23 \mu \mathrm{mps} / \mathrm{mg}$ after 21 hours in $30 \% \mathrm{KOH}$ at $80^{\circ} \mathrm{C}$. This current level increased slightly at $1200 \mathrm{mV}$ (32 $\mu \mathrm{mps} / \mathrm{mg})$ and at $1300 \mathrm{mV}(50 \mu \mathrm{amps} / \mathrm{mg})$. At $1400 \mathrm{mV}$, there was visible oxygen evolution at a current density of about $57 \mathrm{~mA} / \mathrm{cm}^{2}$. Subsequently, the electrode was set at $600 \mathrm{mV}$ vs. RHE and held for 112 hours. A low cathodic current was observed

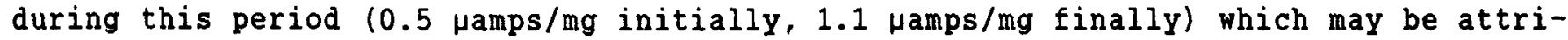
buted to oxygen impurity in the nitrogen. Subsequent measurement of the anodic current at potentials above $1.0 \mathrm{~V}$ showed about an order of magnitude decrease at all potentials. Post-test examination of the electrode sample revealed significant morphological changes, e.g. gross cracking of the catalyst layer, shrinkage and some delamination. These observations may account for the decreased anodic current levels in the final series of measurements. 


\section{OXYGEN REDUCTION/EVOLUTION PERFORMANCE}

\section{Reference Materials}

Three materials were chosen as points of reference for performance: 108 Pt supported on Vulcan $\mathrm{XC}-72$ carbon and $10 \% \mathrm{Pt} / \mathrm{Au}$ for exygen reduction, and $\mathrm{NiCO}_{2} \mathrm{O}_{4}$ for oxygen evolution. All of these are commercially prepared catalysts. The $10 \% \mathrm{Pt} / \mathrm{C}$ represents Giner, Inc. electrode technology as an internal baseline. The 10\% Pt/Au has been used by United Technologies in alkaline fuel cells (ref. 11) and was intended to provide an external reference point; more development was required to achieve satisfactory performance with this material, therefore. The performance of both of these materials as oxygen reduction electrodes is shown in Figure 1 .

$\mathrm{NiCO}_{2} \mathrm{O}_{4}$ purchased from Basic Volume LTD. (CheMaterials, U.K.) has, to date, not exhibited performance levels described in the literature for this material as an oxygen evolution catalyst. Some progress has been made, however, and better performance is anticipated. The most recent performance obtained for $\mathrm{NiCO}_{2} \mathrm{O}_{4}$ is shown in Figure 1.

\section{Candidate Catalysts}

The $\mathrm{CdPd}_{3} \mathrm{O}_{4}$ preparation was tested for both oxygen reduction and oxygen evolution performance in $30 \% \mathrm{KOH}$ at $80^{\circ} \mathrm{C}$. The results in either mode do not suggest the potential for significant catalytic activity, especially for oxygen reduction, e.g. at a current density of $10 \mathrm{~mA} / \mathrm{cm}^{2}$ the electrode exhibited a reduction potential of about $0.6 \mathrm{~V}$ and an oxidation potential of about $1.5 \mathrm{~V}$ vs. RHE.

The most conductive preparation of $\mathrm{PbPdO}_{2}(112 \mathrm{~K}$ ohm-cm) was still too to make a practical electrode with the pure material. A sample of $\mathrm{PbPdO}_{2}$ on carbon (ref.2) was tested as an alternative method of evaluation. This material, as shown in Figure 2, appears to show catalytic activity for oxygen reduction beyond the activity of carbon alone. This catalyst candidate material will be investigated further if it can be deposited successfully on a non-carbon support.

CoTMPP was prepared on carbon supports also, as a method of evaluation. The method described by Scherson, et al (ref.12) was tried using vulcan XC-72 carbon and a higher surface area carbon, Anthralur KC (Lurgi). The oxygen reduction performance, although better than carbon alone, did not approach the performance reported by Scherson. These results are shown in Figure 2. An early attempt to deposit CoTMPP on a low-surface area non-carbon support, Material $A$, was at best very non-uniform; $X-$ ray dot mapping for example, did not show evidence of cobalt. This approach will be pursued further with higher surface area non-carbon supports.

$\mathrm{Na}_{x} \mathrm{Pt}_{3} \mathrm{O}_{4}$ was prepared by solid state reaction of $\mathrm{PtO}_{2}$ and $\mathrm{Na}_{2} \mathrm{CO}_{3}$. The value of $\mathrm{x}$ was determined to be about 0.8 (ref. 2). The surface area and particle size, obtained have not yet been determined. The bifunctional oxygen electrode performance, shown in Figure 1, suggests that this material is suitable for further development.

The $\mathrm{Pb}-\mathrm{Ir}$ pyrochlore preparation was based on a procedure described by Horowitz, et al for $\mathrm{Pb}_{2}\left(\mathrm{Ru}_{1-x} \mathrm{~Pb}_{\mathrm{x}}\right)_{7-y}$ (ref. 13). After firing at $400^{\circ} \mathrm{C}$ the material was still amorphous. Consequently to determine the structure, a sample was fired at $500^{\circ} \mathrm{C}$ for 2 hours; X-ray diffraction analysis (ref.2) gave broad lines for the pyrochlore pattern and a lattice parameter of $a=10.396 \pm 6 \AA$. The composition proposed is 
$\mathrm{Fb}_{2}\left(\operatorname{Ir}_{1.33} \mathrm{~Pb}, 67\right) 0_{7-y}$. The original material (fired at $400^{\circ} \mathrm{C}$ ) was used to make electrodes for the testing described here. The bifunctional oxygen electrode performance, shown in Figure 1, also suggests promise for further development. The corrosion test results described earlier may indicate some instability, however. our initial approach will be to try a higher firing temperature, as used for the analytical sample.

\section{ACKMONLEDGKENT}

This work is supported by the NASA-Lewis Research Center under the direction of Dr. William Fielcer (Contract No. NAS3-24635).

\section{REFERENCES}

1. Giner, J. and Hunter, C.: "The Mechanism of Operation of the Teflon-bonded Gas Diffusion Electrode: A Mathematical Model," J. Electrochem. Soc., vol. 116, 1969, pg. 1124-1130.

2. Chamberland, B.L.: Professor of Chemistry, University of Connecticut. Professor Chamberland has provided materials analysis support as weil as guidance in the selection of materials and preparation methods.

3. Giner, J. and Smith, S.: "A Simple Method for Measuring the Polarization of Hydrophobic Gas Diffusion Electrodes," Electrochem. Technol., vol. 5, 1967, pg. 59-61.

4. Giner, J.: "A Practical Reference Electrode," J. Electrochem. Soc., vol. 111, 1964, pg. 376-377.

5. General Electric, "Hydrocarbon-Air Fuel Cells," Technical Summary Report No. 10, USAERDL Contract DA44-009-AMC-479(T), AD649895, pg. 2-7 and 4-10, 1966.

6. Lazarev, V.B. and Shaplygin, I.S.: "Properties and Structure of $\mathrm{PbPdO}_{2}, " Z h$. Neorg. Khim., vol. 24, 1979, pg. 885-889.

7. Lazarev, V.B. and Shaplygin, I.S.: "Reactions of Palladium Oxide With Oxides of Group V Elements," $Z$ h. Neorg. Khim., vol. 19, 1974, pg. 2388-2390.

8. Lazarev, V.B. and Shaplygin, I.S.: Zh. Neorg. Khim., vol. 23, 1978, pg. 291.

9. Schwartz, K.B.; Prewitt, C.T.; Shannon, R.D.; Corliss, L.M.; Hastings, J.M.; and Chamberland, B.L.: "Neutron Powder Diffraction Study of Two Sodium Oxides: $\mathrm{Na}_{1} . \mathrm{OPt}_{3} \mathrm{O}_{4}$ and $\mathrm{Na}_{-73} \mathrm{Pt}_{3} \mathrm{O}_{4}, "$ Acta Cryst., vol. 38, 1982, pg. 363-368.

10. Shannon, R.D; Gier, T.E.; Garcia, P.F.; Bierstedt; Flippen, R.B.; and Vega, A.J.: "Synthesis and Properties of Platinum Metal Oxides of the Type $\mathrm{M}_{\mathrm{x}} \mathrm{Pt}_{3} \mathrm{O}_{4}$," Inorg. Chem., vol. 21, no. 9, 1982, pg. 3372-3381.

11. Singer, J. and Srinivasin, V.: "Evaluation Parameters for the Alkaline Fuel Celi Oxygen Electrode," NASA Technical Memorandum 87155, November, 1985.

12. Scherson, D.A.; Gupta, S.L.; Fierro, C.; Yeager, E.B.; Kordesch, M.E.; Eldridge, J.: Hoffman, R.W.; and Biue, J.: "Cobalt Tetramethoxyphenyl Porphyrin-Emission Mossbauer spectroscopy and $\mathrm{O}_{2}$ Reduction Eiectrochemical studies," Electrochim. Acta, vol. 28, no. 8, 1983, pg. 1205-1209.

13. Horowitz, H.S.; Longo, J.M. and Lewandoski, J.T.: "Lead Ruthenium oxide, $\mathrm{Pb}_{2}\left[\mathrm{Ru}_{2-x} \mathrm{~Pb}^{4}\right] \mathrm{O}_{6}, 5, "$ Inorganic Syntheses, McGraw-Hill, New York, pg. 69-72. 


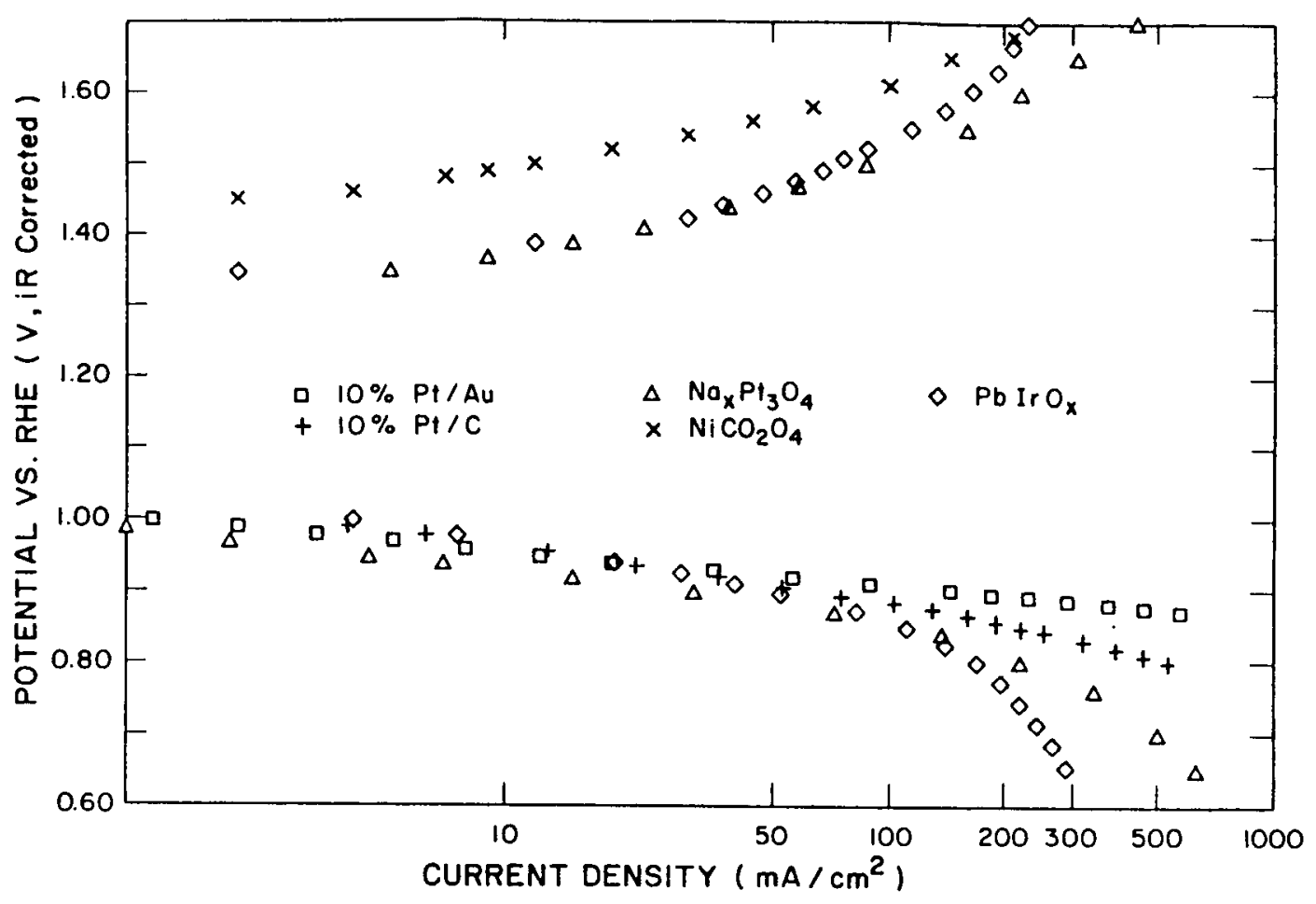

FIGURE I. OXYGEN REDUCTION / EVOLUTION $\left(30 \% \mathrm{KOH}, 80^{\circ} \mathrm{C}\right)$

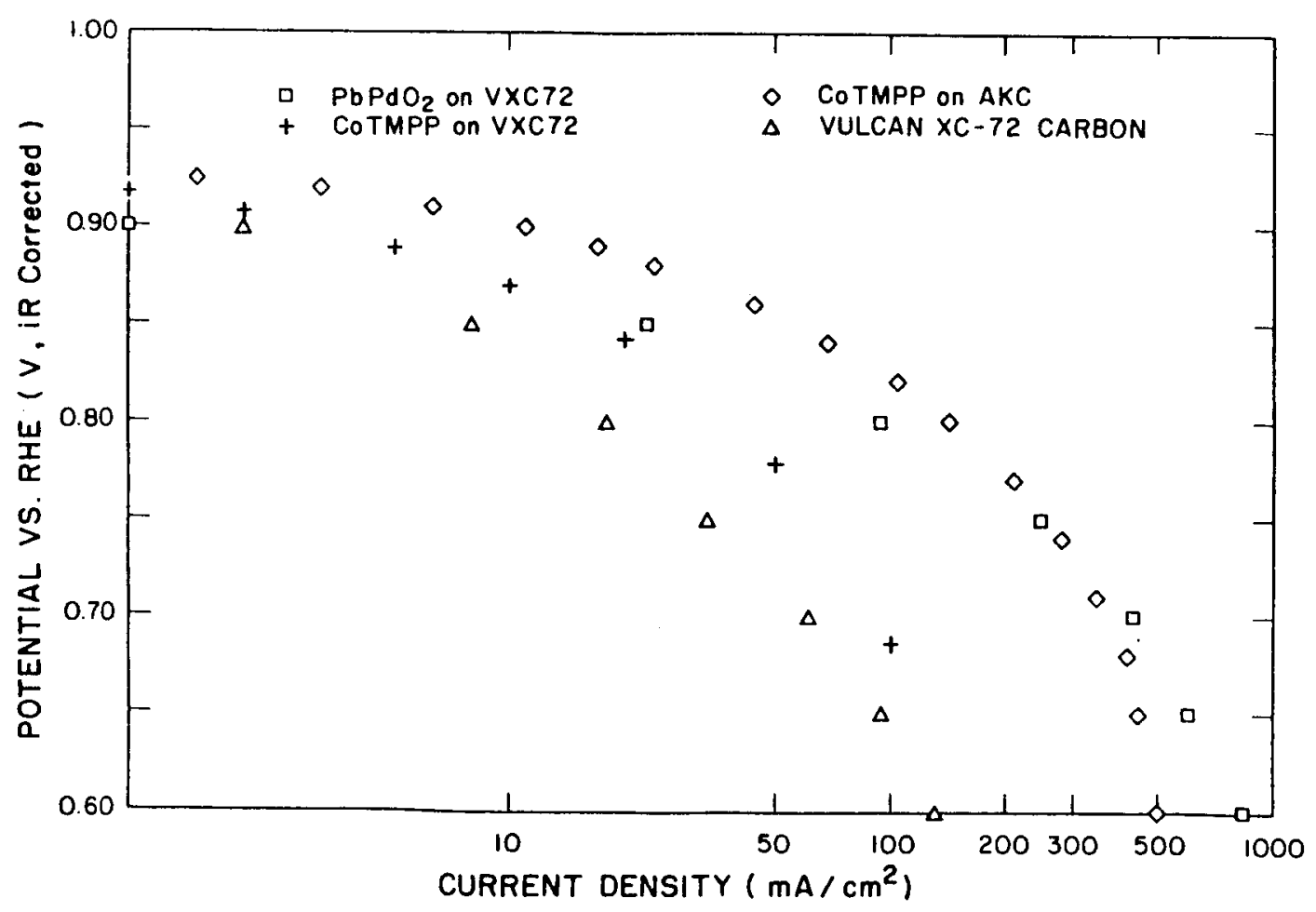

FIGURE 2. OXYGEN REDUCTION $\left(30 \% \mathrm{KOH}, 80^{\circ} \mathrm{C}\right)$ 